\title{
The School and the Teacher Autonomy in the Implementing Process of Entrepreneurship Education Curricula
}

\author{
Kaarina Sommarström *(D), Elena Oikkonen (D) and Timo Pihkala (D) \\ School of Engineering Science, Lappeenranta-Lahti University of Technolgy, Yliopistonkatu 34, \\ 53850 Lappeenranta, Finland; elena.oikkonen@lut.fi (E.O.); timo.pihkala@lut.fi (T.P.) \\ * Correspondence: kaarina.sommarstrom@student.lut.fi
}

Citation: Sommarström, K.; Oikkonen, E.; Pihkala, T. The School and the Teacher Autonomy in the Implementing Process of Entrepreneurship Education Curricula. Educ. Sci. 2021, 11, 215. https://doi.org/10.3390/ educsci11050215

Academic Editor: Neil Gordon

Received: 19 March 2021

Accepted: 27 April 2021

Published: 3 May 2021

Publisher's Note: MDPI stays neutral with regard to jurisdictional claims in published maps and institutional affiliations.

\begin{abstract}
The purpose of this study was to examine the utilization of the opportunities offered by teacher and school autonomy in entrepreneurship education with companies involved. The research question was: How do schools and teachers use their autonomy in the implementation of entrepreneurship education? This research question was complemented by two additional research questions that were: How does teacher autonomy benefit the implementation of entrepreneurship education? and How do teachers want to utilize autonomy in teaching? This qualitative study used content analyses and the data were collected via semi-structured interviews, with a total of 35 people from 23 schools in Finland. The findings show that school and teacher autonomy brought excellent results in implementing entrepreneurship education and, in these cases, the message of the curriculum worked as fuel for the activities carried out by the school and the teachers. At the same time, some groups of schools and teachers disregarded the message of the curriculum for a set of reasons. Hence, the educational authorities nationally and locally need to consider the balance between autonomy and the core curriculum and weigh the pros and cons of the situation. The study suggests further research on teachers' perceptions of the relationship between the curricula expectations and implementation of entrepreneurship education.
\end{abstract}

Keywords: entrepreneurship education; autonomy; teacher; school-company interaction

\section{Introduction}

The objective of this article is to analyze school and teacher autonomy and its effects on the implementation of the curriculum, especially on the expectations set on entrepreneurship education. School autonomy is a form of decentralization in which schools can decide on some issues related to teaching and education [1-3]. School autonomy depends on and is influenced by national legislation, relationships with the authorities, and partnerships with educational management organizations and community-based organizations [4,5]. In other words, the national curriculum allows for deviations, and schools can therefore determine their own actions within those areas. In addition to this, municipality-level authorities can influence school autonomy by means of their own regulations [6,7].

There is very little research on the role of autonomy on the implementation of entrepreneurship education. This is surprising because, while the curriculum prescriptions seek to unify schools' attempts to implement entrepreneurship education in the whole school system, the autonomy of schools and teachers is regarded as important features of successful schools. In this study, we turned our attention to the autonomy of teachers in basic education, that is, teachers working with youth of 13-16 years old, and examined how entrepreneurship education is carried out. The main research question was: How do schools and teachers use their autonomy in the implementation of entrepreneurship education? The main research question is complemented by two additional questions. The first additional research question was: How does teacher autonomy benefit the implementation of entrepreneurship education? The second additional research question was: How do teachers want to utilize autonomy in teaching? 
In this study, the data show three basic ways in which the informants used their autonomy in regard to entrepreneurship education: exceeding the expectations set by the curriculum, working on an equal footing with the curriculum, and disregarding the curriculum.

The paper makes two important contributions to the current literature on entrepreneurship education: first, it shows that school and teacher autonomy has leverage concerning the implementation of entrepreneurship education. This seems to be the factor that allows the schools to behave opportunistically, follow their own concepts of implementation, and come up with local solutions for entrepreneurship education. Second, autonomy seems to be a force related to both excellent results and no results in the implementation of entrepreneurship education. Even more interestingly, schools and teachers that followed the curriculum closely and fell in between the two autonomous groups did not talk about their autonomy. It seems that, for the normal, expected outcome, the bare concept of autonomy seems futile. These results have multiple implications on the research of entrepreneurship education and on the promotion of entrepreneurship education.

The structure of the article is as follows: First, a presentation of the conceptual framework addressing the concept of the curriculum and teacher autonomy. Second, we briefly highlight how entrepreneurship education is positioned in the curriculum. After that we present the methodology for this study, as well as data collection and analysis. This is followed by a presentation of the findings and a discussion. Conclusions complete the study.

\section{Literature Review}

School autonomy is considered to work best and be conducive to student achievement in well-developed systems that hold schools accountable for their actions [8,9]. Hanushek et al. [10] agree, stating that accountability and the development of the educational system are considered to be prerequisites for autonomy. Accountability can have many meanings but, within the context of the school, it refers to school personnel being responsible for their actions $[1,11,12]$.

Teacher autonomy is a complex concept, as the literature recognizes a range of conceptualizations [12-17]. Teacher autonomy can appear as the possibility to increase one's own knowledge and skills through development and rigorous training [14,16]. It is common for many teachers to treat autonomy as a synonym for independence, which allows teachers to decide about their teaching in isolation from others [15]. Teacher autonomy is also regarded in literature as educational autonomy; that is, teachers have the possibility to prepare their lessons independently, choose textbooks and topics to be taught, select teaching methods, engage in time planning, and assess and evaluate students $[5,15,17]$.

Research on teacher autonomy shows that teacher autonomy provides benefits, such as better learning outcomes of learners $[1,18,19]$, motivation and job satisfaction of teachers [12,16,17], and flexibility in teaching and learning [16]. Hanushek et al. [10] argued that, at best, autonomy allows teachers to use localized knowledge to improve performance and cooperate with outside actors in emerging opportunities, but it can also cause local schools to strive for goals beyond general standards [10].

Teacher autonomy is regarded necessary for schools to achieve learning success $[13,20]$. Autonomy empowers teachers, supporting their work satisfaction and professionalism [21]. In the framework of teacher and school autonomy, it is understandable that entrepreneurship education varies among schools. While some schools have disregarded entrepreneurship education, many schools have embedded entrepreneurship education in their school system, e.g., involving outside companies to provide students with a realistic picture of business life.

The concept of autonomy has been well covered in entrepreneurship education research [22-26]. These studies have, however, concentrated principally on students' autonomy as a learning outcome of entrepreneurship education. Entrepreneurship education in cooperation with companies gives students the opportunity to actively participate in companies' activities. School-company cooperation gives students the opportunity to see, 
touch and feel [27-30]. Chiu [31] studied the Nordic model of entrepreneurship education and raised educational institutions' full autonomy and flexibility in the implementation of entrepreneurship education as a special feature in Nordic countries. The benefits of autonomy were related to higher teacher commitment due to the decentralized system [13,31]. However, Chiu [31] noted that the high level of autonomy leads to less ability of policy makers to monitor and control the implementation of entrepreneurship education. While school and teacher autonomy have been recognized as beneficial features for entrepreneurship education, a wide range of research has suggested that the norms and expectations set by the curricula and school and teacher autonomy are constantly seeking balance $[14,32,33]$.

Schools must meet the requirements of the core curriculum regarding the subjects and their scope. The Finnish core curriculum recommends schools include entrepreneurship and working life in their programs [34]. As a cross-curricular theme, entrepreneurship education should be embedded in all subjects and also in the operating culture of schools, but it can also be an optional subject. Nevertheless, the Finnish core curriculum clearly describes seven transversal competence areas that are common to all school subjects; one of these is working life competence and entrepreneurship [34]. This description has a clear message: students should be given the opportunity to become acquainted with working life and gain experience in entrepreneurship and business life. No specific guidelines have been given to schools on how to realize school-company cooperation. Instead, schools and teachers are free to apply methods of entrepreneurship education as they see fit in their teaching programs. In addition, a school can make decisions about the school culture, optional subjects, or other practical issues. As autonomous professionals, teachers can choose their teaching methods. Regarding the cooperation with external partners, schools can make the decisions or let teachers decide for themselves.

In terms of teacher commitment, Bascia et al. [35] suggested that, even though entrepreneurship is mentioned in the curriculum, teachers who are not committed to entrepreneurship education choose to follow the traditions rather than adapt new things in their teaching. In essence, entrepreneurship education can be considered an educational reform. As such, Fejes, Nylund, and Wallin [36] suggested that entrepreneurship education may suffer because of its young age as a curriculum area. Furthermore, Kelchtermans [37] and Foliard et al. [38] suggested that, in educational reforms, teachers may feel professionally vulnerable, and this may lead to abandoning the new pedagogy. This is even more probable if the new concept seems unclear to the teachers [39]. Finally, in terms of cognitive processing, Bergqvist and Bergqvist [40] suggested that, facing a reform message, teachers either accommodate or assimilate it. According to them, accommodation refers to full systematic processing-internalizing — of the message, while assimilation concerns only heuristic processing of the message. In other words, assimilation refers to being superficially aware of the new message without adopting it [40].

While all the explaining factors may have a role in explaining the implementation of entrepreneurship education, this study focuses on autonomy. In this view, teachers are considered as educational professionals who need to have the freedom to tap into the best solutions and approaches to operate with their students [21] (p. 38). This is especially relevant in the case of entrepreneurship education, that often also includes intensive interaction with outside stakeholders, usually companies. Having an outside actor from the corporate world in the education environment is a challenge to the teachers [41].

\section{Methodology}

\subsection{Method}

This study applied a qualitative research method [42,43], as the focus of the study was to understand teachers' interpretations of entrepreneurship education in the curriculum, and, in that sense, their perspectives on interaction with companies. Qualitative research enables researchers to examine social and cultural phenomena [44]. In this study, we ensured scientific rigor by applying the Gioia method in the analysis [42,43]. The strength 
of qualitative research is to provide an understanding of the phenomena and points of view as seen by the participants $[45,46]$.

The research material was collected from interviews with teachers and principals in basic education in Finnish schools. In Finland, entrepreneurship education has been part of the national curriculum for basic education since 1994. Basic education is part of compulsory education and students are aged between 7 and 16 years. The national curriculum [34] is a guiding document for all schools to follow, and it sets the objectives and core contents of all subjects. In the national core curriculum, entrepreneurship education is described as one cross-curricular theme which needs to be embedded in all subjects and in schools operating culture. In addition, some schools have decided to offer entrepreneurship as an optional subject. The data included a total of 35 people from 23 schools. The schools were intentionally selected from geographically different parts of Finland, including urban and rural areas. This was done to obtain a rich set of material from a large area and not just from one region. As a result, our study included respondents from 19 different municipalities. Four of the municipalities are large cities with more than 100,000 inhabitants. Six are medium sized towns (50,000-100,000 inhabitants) and the remaining nine municipalities have less than 50,000 inhabitants. Out of the informants, 24 worked as subject teachers in various subjects and 11 as principals. Besides acting as heads of their schools, the duties of the principals also included teaching some weekly lessons.

\subsection{Sample}

Semi-structured interviews were chosen, as they allowed the respondents to explain their experiences and thoughts and to highlight their expertise. Semi-structured interviews are also flexible and allow more detailed questions to obtain material if something seems unclear in the course of the interview [47]. According to Elo et al. [48], the interviewer must be careful not to steer the interviewees to respond in a desired direction.

A framework for the interviews was constructed in advance. The interview themes are listed in Table 1. The semi-structured interviews were initiated with questions about visits outside school with the students.

Table 1. Interview themes.

\begin{tabular}{cc}
\hline 1 & How many visits are made per school year? How many other visits to, for instance, \\
museums, science centers or other destinations? \\
2 & What other kind of cooperation takes place with outside actors? \\
3 & How do you get in touch with companies? Who takes an active role in arranging \\
4 & cooperation or visits? \\
5 & What are the practical arrangements for the visits? \\
6 & What is the purpose of the visits? How interested is the teacher in this kind of teaching? \\
7 & Which companies are located in the vicinity? \\
8 & How do the classes plan the visits in advance? \\
9 & How do the classes process the visits afterwards? \\
10 & What are the teachers' attitudes to and thoughts about the visits in general?
\end{tabular}

The questions focused on teachers' experiences of entrepreneurship education, especially school-company cooperation. During the interviews, further questions followed the informants' responses. When selecting the informants, it was ensured that all the interviewees were in fact teachers or principals in basic education and, therefore, were expected to conduct entrepreneurship education. However, it was a deliberate decision not to focus merely on informants who are profoundly familiar with entrepreneurship education. Instead, most of the teachers in the study were not educated to work as entrepreneurship education teachers. For this reason, the data include plenty of variety in terms of experiences of entrepreneurship education. The duration of the interviews varied from 17 to $81 \mathrm{~min}$. The interviews were conducted in Finnish or Swedish, depending on the language used in the school. The interviews were audio-recorded and transcribed 
verbatim. For the purposes of this paper, the selected quotations have been translated into English and adjusted slightly to make them more comprehensible in English.

\subsection{Data Analysis}

To analyze the data, we applied the Gioia method [42,43]. Content analysis is a method for analysing written or verbal messages [49]. Content analysis is a suitable tool for obtaining an understanding of the meaning of communication between the interviewer and the interviewee [50]. Through content analysis, the words, phrases, and statements can be tested [51]. Excel tables were used to organize the data, following the principles of qualitative content analysis [51]. The statements were divided into categories according to their context and transferred to the table, making it possible to distinguish new insights from the categorized data [52].

The data were read carefully several times. In the initial analysis, the informants' comments concerning choices for and against the implementation of entrepreneurship education in cooperation with companies were carefully examined and compared with other corresponding explanations $[42,43]$.

Next, in the second-level analysis, the categories were formed to include issues such as the national core curriculum, school curriculum, school autonomy, teacher autonomy and teachers' practices. Through these themes, an understanding emerged of the opportunities and constraints of entrepreneurship education, as well as further curricula-based interpretations. The categories were further split into more detailed categories. Finally, similar and different statements were gleaned from the worksheet in accordance with comparative analysis. Based on the analysis, the respondents' comments on the extent of entrepreneurship education were categorized into three groups and named as: adopting and adapting entrepreneurship education, following the curriculum, and disregarding entrepreneurship education. The categorized findings are presented in the chapter, illustrated with quotations from the interviews.

\section{Findings}

The findings of the study seemed to suggest that, as informants, the teachers and principals could be divided into three categories in terms of how they use autonomy related to entrepreneurship education. The first category comprised of the first adopters and adapters of entrepreneurship education, the second group followed recommendations of the core curriculum by making a few visits, and the third disregarded entrepreneurship education through autonomy. The results are explained in more detail in the sections below.

\subsection{Adopting and Adapting Entrepreneurship Education}

In the data, there were several principals and teachers that explained their experiences of entrepreneurship education vividly. These comments create the first category. One of the informants, the principal in a school where all classes have some cooperation with companies, explained their practices. He seemed satisfied with the system and thus devotedly explained the freedom allowed by the national core curriculum and other authorities $[1,53]$.

Not all schools have advanced as much as our school. My superiors have given me the approval to do it in this way. Many schools do a lot of activities, but the activities are not as well planned as they are in our school. The others have activities that are more fragmented and random because it is not set in the national curriculum.

(Interviewee 4, principal)

Here, the focus is on the whole school. The principal in the excerpt above was very competitive [20]. He compared his school to others and was satisfied that he can implement his own systematic plan that covers the whole school and has secured success. It seems that the principal sought to strive for goals beyond general standards [10]. Fur- 
thermore, the example also highlights the benefits of autonomy as the principal sought to exceed the expectations set by the curriculum. Another approach consists of particular entrepreneurship-focused classes. This means there are classes in each of the grades that have entrepreneurship as an optional subject, and they interact and cooperate with companies. These classes work beyond normal classes and differ from other classes that have entrepreneurship education embedded in other subjects. In this sense, a principal uses their autonomy to organise the teaching in the school independently [41]. The school hours or the number of lessons are the same as in other classes, the difference is demonstrated in the combination of subjects. A principal who works at such a school explained how those classes have been working:

If I think about the curriculum and these areas of transversal competences, what is clearly highlighted is that during their three-year long school time these classes clearly participate in the competence area of working life skills and entrepreneurship as well as the other competence areas. They will surely have obtained working life skills needed today and certainly in the future. If we read that chapter of the school's operating culture and underline everything we already have implemented, then it is a pretty well-underlined document.

(Interviewee 11, principal)

The principal was seemingly proud of the accomplishments of her school-the freedom to implement the curriculum created a deep commitment to fulfil all the expectations [21,31]. The principal described the operating culture as inspiring and explained that teachers at school dare to take challenges and start something that may not be crystal clear at the beginning but will be accomplished together with students [15]. In other words, any teacher regardless of the teacher's professional teaching subject is capable to act as a contact person for a host company and develop practices in class-company cooperation. Cooperation is part of the schoolwork for those classes, and it is supported by the principal and colleagues $[3,54]$. She continued as follows:

Perhaps it shows that the teachers agree that they should not be the only ones who the students seek answers from, but together they [the teacher and the students] seek answers and find things out. This is good and may on the other hand even be better so. In recent years we have changed our entrepreneurship education, and at the moment teachers in arts, Finnish and religion are responsible for our entrepreneurship-focused classes. In the past, I as entrepreneurship education teacher was responsible for all those classes and had to manage all their projects. I found it pretty heavy going.

(Interviewee 11, principal)

Hanushek et al. [10] emphasized the teachers' autonomy to use localized knowledge to improve performance. The citation above suggests that the teachers used their autonomy to create knowledge together with their students, turning the learning situation into a sociallyconstructed process [55]. Innovative teachers conducted projects and made company visits to acquaint students with business and working life $[53,56]$. They planned the company visits within the timetable of their own lessons as far as possible. Inevitably, this did not work in all situations, and teachers needed to negotiate with other teachers about rescheduling lessons and other issues. They seemed to find it laborious at times, but they were enthusiastic and committed to continue in their own field, arranging company visits [31]. They usually managed to make several visits during the school year, but sometimes the number of visits remained minimal, as one of the enthusiastic teachers put it in words:

Within entrepreneurship education, we go on a number of visits to companies. It varies depending on how they fit into our schedules and how much I am able to do. And we usually visit companies during the 9th grade [students around 15 years] within the framework of social science. There is a section about entrepreneurship and the curriculum recommends visiting different kinds 
of companies as much as this can be arranged. Our visits are in line with the national curriculum and the school curriculum. Let's say we do not make a visit on some school year. In such case, we can say that the teacher is going against the guidelines of the curriculum. We should go outside school to study as much as possible. But sometimes it is not possible, mostly due to the schedules.

(Interviewee 12, teacher)

In the excerpt above, something seems to occur in the discourse: when teaching took place within the frames of the curriculum, the teacher talked about 'us', but, if the curriculum was not followed, it was about the teacher. Even if the school followed the curriculum, the teachers' autonomy to make up their own minds was not limited. Another enthusiastic teacher felt that she was supported and helped by another teacher who was also interested in cooperating with companies [5]. She explained that they were interested in school-company interaction, they managed to visit interesting companies and stated that the students had also enjoyed the collaboration. She finished by adding:

You really need to be active yourself. I don't think a fraction, if anything of this would be done, if you were alone. At least two teachers are needed, absolutely.

(Interviewee 26, teacher)

\subsection{Following the Curriculum}

The second category consists of respondents who described organizing some entrepreneurship education events with external actors. These respondents more or less followed the main message of the core curriculum without striving for anything new or extraordinary $[40,57]$. Some of them worked in schools that have entrepreneurship education as optional studies (for instance, at a certain grade), which offers the students the possibility to choose it $[24,26]$. Implementation depended on the teacher's capability and interest, be it interaction with companies or keeping things just in classroom settings $[14,58]$. Some teachers explained that students actively participated in finding interesting companies that they could visit [57]. One of the informants responsible for entrepreneurship education explained the students' participation in the selection of companies:

Often in the last few years, we have had visits to companies which the students have selected. They followed their gut feelings a bit when they chose a company. It was like that for the bakery industry. A group chose McDonald's of all possible companies. And I said, of course we can go and see it.

(Interviewee 14, teacher)

Some schools seemed to consider visits to public places, such as science centres or museums, as sufficient outside activities from school. The purpose of such visits was to strengthen an understanding of a phenomenon; teachers seemed to interpret the message of the core curriculum superficially, in a self-satisfying way [36,40], by taking field trips somewhere outside school to bring a glimpse of real life into the school world. These visits seemed to be subject-related, for example a phenomenon in physics or dramatic art in arts and culture.

In these schools, students are annually offered some opportunities to go on visits, which they plan and put on their school calendar in the autumn when the school starts. In other words, it is important that the visits take place outside school. One of the teachers explained:

Every student makes at least five study visits per school year, so for example, all of the students in the 7th grade usually visit the science center [name of the science centre], all the students in the 8th grade visit the art museum [name of the art museum] and all of the students in the 9th grade visit the Finnish parliament and the District Court. All students visit the yearly book fair. We have many visits in our programme and we have a system everyone makes at least five 
visits. But we do not have regular company visits, we have not taken that in the program.

(Interviewee 2, principal)

Another informant explained a similar standard pattern that was used in his school. He seemed to be satisfied with the system, but also noted company visits were less common. The informant explained the practice of the activities outside school:

Basically, the students in the 7th grade have just the orientation day in [name of place]. In the 8th and 9th grade, it becomes more advanced in various subjects. Of course, there could be an industrial visit or something similar, at least once a year.

(Interviewee 24, teacher)

\subsection{Disregarding Entrepreneurship Education}

The third category comprises respondents who appeared to disregard the message of the core curriculum $[36,59]$. They were aware of it but considered it only a recommendation. They appeared to believe that the curriculum provides them freedom to choose whether to adopt entrepreneurship education in their teaching system or not and willingly leave it out. In their opinion, they have a well-functioning school system, and their most important task is to provide students with sufficient knowledge to become good citizens. They produced a plethora of reasons why they do not need to seek more interaction with companies [60]. This category includes teachers and principals that had good excuses not to adopt entrepreneurship education and to have less interaction with companies. Some seemed to foster the idea that a mandatory work practice program compensates for their missing entrepreneurship education. Interaction with companies was a strange thought, as one informant explained:

I do not think we will go on any company visits. But I know that students have the opportunity to learn about business during their practical training period when they spend two weeks in a company in the 9th grade or so... There they have company contacts, but not in normal teaching, no.

(Interviewee 1, principal)

One of the informants argued that minimized company interaction is not only due to the school policy. She stated that companies should actively contact schools and invite cooperation. Then, it would be easier for a school to select some events. Some other teachers agreed with the recommendations of the core curriculum but always found a reason why they could not begin taking a new approach in their teaching. They followed a hidden curriculum, with the same pattern from year to year [35,61]. In general, these schools have not adopted entrepreneurship in their school programmes. One of the principals saw the situation like this:

One might be a little surprised to have a group of 20 surly 14-year-old students on a visit, and no one may be greatly interested. The person who receives visitors has a responsibility to be prepared and to understand the target group and its mission. If you do not know these companies and do not really know what they have to offer, it can happen that you go there and realize that it was completely wasted time.

(Interviewee 2, principal)

Uncertainty seemed to prevail among teachers in this category, as the previous quotation shows. Another teacher, who knew the recommendations of the curriculum well and was able to accept interaction with companies in principle, acknowledged that it is, nevertheless, a big step to take. She explained her opinions and thoughts as follows:

It is all about the complexities since there are no ready channels. It means that even if you had a thought that this would be good, it may not be implemented 
when you face all the obstacles along the way. If there were clear models and ready channels, then you perhaps would do it. I do not think the reason is that teachers do not want to, but I think, because it takes too much effort and resources to implement it.

(Interviewee 17, teacher)

In these cases, autonomy was used to make it easier for the teacher-following the curriculum would be too laborious. This suggested that the school and teachers considered the message of the curriculum but decided not to follow it [35]. For some teachers, entrepreneurship and working life aspects of the curriculum were difficult to understand. They claimed the text in the curriculum about entrepreneurship education is long and complex and its implementation is not clearly expressed [57,62]. The content of the curriculum could be clearer and more direct, as one informant said:

It [the curriculum] is incoherently written. It is very difficult to deal with if you think a new teacher should read it and get something out of it. I think we have big problems with the new curriculum. The previous curriculum was better. I think the idea is good, but problems arise when there are so many people who have written it, the text is not easy to read. It contains 350 pages, I have not read it from cover to cover, but I have read many parts quite carefully and noticed that it is difficult. You may understand the idea, but it is written in a very difficult way. I wish that in [name of the municipality] we could have a more specific local curriculum. Such things are more important to a teacher than all the nice words about how everything should be done.

(Interviewee 24, teacher)

The interview material revealed that teachers may alter their views on company interaction. For example, a person who previously did not wish to be in any way involved in entrepreneurship education suddenly became surprisingly interested in it. This change in heart required something to trigger a new direction in thinking and alleviate fear and uncertainty shackling teachers' attitudes. The trigger may have been a positive experience, but exposure to such a positive experience often occurred through an external factor, so teachers were less likely to expose themselves to what they are uncertain of. One informant described her own experience of how she had initially thought she could not be interested in entrepreneurship education and cooperate with companies. She explained:

I teach religion. When the school adopted entrepreneurship into the school programme as an optional subject, I was asked if I could teach that subject. At first, I said, well, I have never imagined myself as an entrepreneur or anything like that. But then, I usually get excited about new things and I cannot say no to emerging opportunities. So, I decided to try and noticed that it totally inspired me.

(Interviewee 11, teacher)

The direction of the shift from one category to another can also happen in reverse: starting from an attitude of working with companies to not wanting to have anything more to do with them. In such cases, there may not have been any support from the principal or other teachers and the teacher has struggled to organize the company visits alone. One informant explained how her energy declined and she stopped:

It became tougher and the municipality only paid for travel on public transport, and still more, the teachers had to organize the tickets. So, it took more time and the students sometimes had to walk a long way from a bus stop to the visiting destination. Then, the students came home later than normally and began complaining. Also, if one teacher has a visit that takes several hours, and the students should have lessons in other subjects at that time, it is a problem. We would have had to reschedule the lessons with other teachers. So, after some attempts, I thought that no, I can no longer cope with that.

(Interviewee 20, teacher) 
If a teacher was alone trying to help students become familiar with companies and provide them with entrepreneurship and working life skills, it proved to be very cumbersome and even impossible. It was easier when the whole school was committed and shared the challenges.

\section{Discussion of the Results}

Efforts made in promoting the status of entrepreneurship education in national curricula have been based on the idea this would help guarantee the implementation of entrepreneurship education in schools [63]. The findings in our study challenge this assumption. It would seem advisable to settle the balance between the expectations set in the curriculum and the school and teacher autonomy in the daily work in schools. In this paper, we focused on the school and teacher autonomy on the implementation of entrepreneurship education. Our analysis suggests three approaches to the curriculum: teachers and schools using their autonomy to do more than expected, doing only the expected, or using their autonomy and refusing to do what is expected.

Our study seems to indicate that teachers' and schools' autonomy is an important factor in determining the implementation of entrepreneurship education. At its best, autonomy made it possible for schools to embrace opportunities, follow their own concepts of implementation, and come up with local solutions for entrepreneurship education. However, autonomy also brought an element of surprise as, in some cases, the outcomes of autonomy appeared counterproductive towards entrepreneurship education. That is, in the implementation of entrepreneurship education, autonomy seemed to be a force related to both excellent and non-existing results. While autonomy seemed to be a source of motivation, commitment, and competitiveness in schools, it also left room for ignorance concerning the expectations set out in the curriculum. In this sense, the problems with accountability suggested by Chiu [31] are very visible in our study.

The approaches of teachers exceeding expectations indicated firstly that entrepreneurship education was embedded in the whole teaching system, regardless of the teaching subjects. Secondly, in schools that successfully implemented the entrepreneurial aspects of the core curriculum, some classes or subjects emphasized entrepreneurship. Thirdly, it was important that some teachers in the school wanted their students to become acquainted with entrepreneurship and working life and, from the interviews, it was clear that some teachers pursued this. These schools accommodated the national core curriculum very well. In addition, as autonomous schools, they created their own systems to integrate entrepreneurship education in the schoolwork. In their view, the curriculum offers a good opportunity for this, as it already includes entrepreneurship and working life skills as one of the transversal competence areas and recommends cooperating with surrounding companies to provide students with working life skills [36]. The teachers seemed to feel that they were rewarded for their effort when they saw their students enjoy learning $[13,20]$. Our data suggest that, in some cases, the principals even asked for permissions to exceed the expectations of the curriculum. These cases show how the curriculum can be a starting point for school-level activities. To make this happen, co-operation at many decisionmaking levels is called for, involving at least teachers, principals, and their superiors. We suggest further research to uncover the decision-making chains related to these patterns.

The teachers who followed the norms of the core curriculum did not change their programs often. Year in year out, they made some visits outside school and wanted to continue this $[40,64]$. These visits may be local events, for example, or events between schools. They did not necessarily contribute to entrepreneurship education, but nevertheless were an excursion into society from school and were supported by teachers. Teachers seemed to have the authority to decide the number of visits each student is entitled to make during the school year. They assimilated the core curriculum's message and felt that they followed the norms [40]. Strikingly, this group of teachers was familiar with the curriculum and tried to follow it. However, in doing so, they did not appear to find the possibility of autonomy important. This finding is significant as it shows that even if the schools appeared to fulfill 
the curriculum, their activities clearly did not meet the implicit expectations. It is important to determine which aspects of the curricula, or the ways they are communicated, lead to superficial interpretations [40] of the curriculum message. Further studies are needed concerning the teachers' perceptions of the relationship between the curricula expectations and the implementation of entrepreneurship education.

Teachers who disregarded the curriculum message formed a third group. In their view, there are sufficient training periods in the current studies to meet the expectations set for entrepreneurship education. Teachers were convinced that students gain sufficient knowledge of working life during those periods and thus the school need not engage in special activities to fulfil the curriculum expectations. This behavior was evidently related to the teachers' negative conceptions of the workload related to entrepreneurship education. That is, these teachers saw many obstacles that made it impossible to collaborate with companies. These obstacles included, for instance, a lack of time, a lack of resources of the school, or the unclear conceptual basis of the curriculum. This group is especially interesting as it seemed to indicate that the messages set in the curriculum did not reach this group of teachers or activate them in any way. It is noteworthy, that entrepreneurship education has been included in the Finnish national core curricula for basic education for more than 25 consecutive years. As such, this should not be a new phenomenon for teachers. Earlier studies $[62,65,66]$ reported that teachers have difficulties in implementing the entrepreneurial aspects of the core curriculum. Our data suggest that, in many cases, these teachers intentionally decide not to follow the curriculum. This situation could lead to an increase in control and accountability of teachers to follow the curriculum, thus limiting their autonomy at work.

The role of the principal was important if the school wanted to bring about some change in, for example, school-company cooperation. If a school uses its autonomy and makes decisions that affect the whole school, it reduces the autonomy of teachers to make their own decisions. If the school management wants the whole school to use a common teaching strategy, the role of the principal is to act as a rapporteur and negotiator of the strategy. Through school autonomy, the whole school can incorporate entrepreneurship education into the teaching program and implement it in cooperation with companies.

\section{Conclusions}

This study sought to examine in which way the autonomy of schools and teachers is related to the implementation of entrepreneurship education. These results have multiple implications on the research of entrepreneurship education and on the promotion of entrepreneurship education. In terms of further research, we suggest that the autonomy of schools and teachers should be taken into account when observing the entrepreneurship education practices in schools. That is, there is a high probability that autonomy is related to the sophistication of the teaching methods used in the implementation of the curriculum, as well as the commitment of the educators. In terms of practical implications, the message is twofold: first, it seems that school and teacher autonomy brings excellent results in implementing entrepreneurship education and, in these cases, the message of the curriculum works as fuel for the activities carried out by the school and the teachers. At the same time, some groups of schools and teachers disregard the curriculum for multiple reasons. The educational authorities nationally and locally need to consider this and weigh the pros and cons of the situation. Should the implementation of curricula be controlled? What would the implementation of entrepreneurship education be if it were carried out by uncommitted teachers?

\section{Limitations of the Present Study and Suggestions for Future Research}

As any study, this study had limitations. First, the data was gathered from one country only. As suggested earlier in this study, teachers in the Nordic countries are quite autonomous in their work. This is likely to affect the generalizability of the results of the study. Nevertheless, the questions of teacher autonomy and the need to control teachers' 
activities is also of wider interest internationally. Therefore, we suggest that our results may be of interest to international readers. Second, the qualitative data was gathered from teachers and principals. Research on the relationship between teacher autonomy and entrepreneurship education is close to non-existent. We suggest that wider quantitative studies are required to observe the mechanisms related to the teachers' autonomous behavior and its effects on entrepreneurship education.

Author Contributions: Conceptualization, K.S., E.O. and T.P.; methodology, K.S.; writing-original draft preparation, K.S.; writing-review and editing, K.S.; supervision, E.O., T.P. All authors have read and agreed to the published version of the manuscript.

Funding: This research received no external funding.

Institutional Review Board Statement: Not applicable.

Informed Consent Statement: Not applicable.

Data Availability Statement: Data available on request due to privacy restrictions.

Conflicts of Interest: The authors declare no conflict of interest.

\section{References}

1. Arcia, G.; Macdonald, K.; Patrinos, H.A.; Porta, E. School Autonomy and Accountability; The World Bank, System Assessment and Benchmarking for Education Results (SABER): Washington, DC, USA, 2011.

2. Barrera-Osorio, F.; Fasih, T.; Patrinos, H.A.; Santibáñez, L. Decentralized Decision-Making in Schools the Theory and Evidence on School-Based Management; The World Bank: Washington, DC, USA, 2009.

3. Urbanski, A. Improving Student Achievement Through Labor-Management Collaboration in Urban School Districts. Educ. Policy 2003, 17, 503-518. [CrossRef]

4. Finnigan, K.S. Charter School Autonomy: The Mismatch between Theory and Practice. Educ. Policy 2007, 21, 503-526. [CrossRef]

5. Haapaniemi, J.; Venäläinen, S.; Malin, A.; Palojoki, P. Teacher autonomy and collaboration as part of integrative teachingReflections on the curriculum approach in Finland. J. Curric. Stud. 2020. [CrossRef]

6. Lundström, U. Teacher autonomy in the era of New Public Management. Nord. J. Stud. Educ. Policy 2015, 2, 28144. [CrossRef]

7. Mausethagen, S.; Mølstad, C.E. Shifts in curriculum control: Contesting ideas of teacher autonomy. Nord. J. Stud. Educ. Policy 2015, 2, 28520. [CrossRef]

8. Sahlberg, P. The Fourth Way of Finland. J. Ed. Chang. 2011, 12, 173-185. [CrossRef]

9. Schneeweis, N.; Lüdemann, E.; Schütz, G.; Woessmann, L.; Westt, M.R. School accountability autonomy and choice around the world. J. Econ. 2010, 99, 283-285. [CrossRef]

10. Hanushek, E.A.; Link, S.; Woessmann, L. Does School Autonomy Make Sense Everywhere? Panel Estimates from PISA; ADB Economics Working Paper Series No. 296; Asian Development Bank: Manila, Philippines, 2012.

11. Oberfield, Z.W. A Bargain Half Fulfilled: Teacher Autonomy and Accountability in Traditional Public Schools and Public Charter Schools. Am. Ed. Res. J. 2016, 53, 296-323. [CrossRef]

12. Parker, G. Teachers' autonomy. Res. Educ. 2015, 93, 19-33. [CrossRef]

13. Averill, R.M. What motivates higher education educators to innovate? Exploring competence, autonomy, and relatedness-and connections with wellbeing. Educ. Res. 2020, 62, 146-161. [CrossRef]

14. Burkhauser, M.A.; Lesaux, N.K. Exercising a bounded autonomy: Novice and experienced teachers' adaptations to curriculum materials in an age of accountability. J. Curric. Stud. 2017, 49, 291-312. [CrossRef]

15. Vangrieken, K.; Grosemans, I.; Dochy, F.; Kyndt, E. Teacher autonomy and collaboration: A paradox? Conceptualising and measuring teachers' autonomy and collaborative attitude. Teach. Teach. Educ. 2017, 67, 302-315. [CrossRef]

16. Erss, M.; Kalmus, V. Discourses of teacher autonomy and the role of teachers in Estonian, Finnish and Bavarian teachers' newspapers in 1991-2010. Teach. Teach. Educ. 2018, 76, 95-105. [CrossRef]

17. Jeong, D.W.; Luschei, T.F. Are teachers losing control of the classroom? Global changes in school governance and teacher responsibilities, 2000-2015. Intern. J. Educ. Dev. 2018, 62, 289-301. [CrossRef]

18. Clark, D. The Performance and Competitive Effects of School Autonomy. J. Polit. Edon. 2009, 117, 745-783. [CrossRef]

19. Rogat, T.K.; Witham, S.A.; Chinn, C. Teachers' Autonomy-Relevant Practices Within an Inquiry-Based Science Curricular Context: Extending the Range of Academically Significant Autonomy-Supportive Practices. Teachers Coll. Rec. 2014, 116, 1-46.

20. Levin, B.; Fullan, M. Learning about System Renewal. Educ. Manag. Admin. Lead. 2008, 36, 289-303. [CrossRef]

21. Pearson, L.C.; Moomaw, W. The Relationship between Teacher Autonomy and Stress, Work Satisfaction, Empowerment, and Professionalism. Educ. Res. Q. 2005, 29, 38-54.

22. Van Gelderen, M. Autonomy as the guiding aim of entrepreneurship education. Educ. Train. 2010, 52, 710-721. [CrossRef]

23. Hannon, P.D. Philosophies of Enterprise and Entrepreneurship Education and Challenges for Higher Education in the UK. Intern. J. Entrep. Innov. 2005, 6, 105-114. [CrossRef] 
24. Hargreaves, E. The practice of promoting primary pupil's autonomy: Examples of teacher feedback. Educ. Res. 2014, 56, 295-309. [CrossRef]

25. Jones, C.; English, J. A contemporary approach to entrepreneurship education. Educ. Train. 2004, 46, 416-423. [CrossRef]

26. Van Twembeke, E.; Goeman, K. Motivation gets yougoing and habit gets you there. Educ. Res. 2018, 60, 62-79. [CrossRef]

27. Cooper, S.; Bottomley, C.; Gordon, J. Stepping out of the classroom and up the ladder of learning. An experiential learning approach to entrepreneurship education. Ind. High. Ed. 2004, 18, 11-22. [CrossRef]

28. Gibb, A. Concepts into practice: Meeting the challenge of development of entrepreneurship educators around an innovative paradigm. The case of the International Entrepreneurship Educators' Programme (IEEP). Intern. J. Entrep. Beh. Res. 2011, 17, 146-165. [CrossRef]

29. Jones, C.; Matlay, H. Understanding the heterogeneity of entrepreneurship education: Going beyond Gartner. Ed. Train. 2011, 53, 692-703. [CrossRef]

30. Pittaway, L.; Hannon, P.; Gibb, A.; Thompson, J. Assessment practice in enterprise education. Intern. J. Entrep. Beh. Res. 2009, 15, 71-93. [CrossRef]

31. Chiu, R. Entrepreneurship Education in the Nordic Countries-Strategy Implementation and Good Practices; In Nordic Innovation Publication 2012; Nordic Innovation: Oslo, Norway, 2012; Available online: https:/ /www.nordicinnovation.org/2013/entrepreneurshipeducation-nordic-countries-strategy-implementation-and-good-practices (accessed on 22 February 2021).

32. Mølstad, C.E. State-based curriculum-making: Approaches to local curriculum work in Norway and Finland. J. Curric. Stud. 2015, 47, 441-461. [CrossRef]

33. Ormond, B.M. Curriculum decisions-The challenges of teacher autonomy over knowledge selection for history. J. Curric. Stud. 2017, 49, 599-619. [CrossRef]

34. New National Core Curriculum for Basic Education, Finnish National Board of Education. 2014. Available online: https:/ /www. oph.fi/en/statistics-and-publications/publications/new-national-core-curriculum-basic-education-focus-school (accessed on 22 February 2021).

35. Bascia, N.; Carr-Harris, S.; Fine-Meyer, R.; Zurzolo, C. Teachers, Curriculum Innovation, and Policy Formation. Curric. Inq. 2014, 44, 228-248. [CrossRef]

36. Fejes, A.; Nylund, M.; Wallin, J. How do teachers interpret and transform entrepreneurship education? J. Curric. Stud. 2019, 51, 554-566. [CrossRef]

37. Kelchtermans, G. Teachers' emotions in educational reforms: Self-understanding, vulnerable commitment and micropolitical literacy. Teach. Teach. Educ. 2005, 21, 995-1006. [CrossRef]

38. Foliard, S.; Le Pontois, S.; Fayolle, A.; Diermann, I. The legitimacy of teachers in entrepreneurship education: What we can learn from a literature review. Contemp. Iss. Entrep. Res. 2018, 9A, 7-23. [CrossRef]

39. Jones, B.; Iredale, N. Enterprise education as pedagogy. Educ. Train. 2010, 52, 7-19. [CrossRef]

40. Bergqvist, E.; Bergqvist, T. The role of the formal written curriculum in standards-based reform. J. Curric. Stud. 2017, 49, 149-168. [CrossRef]

41. Sahlberg, P. The professional educator Lessons from Finland. Am. Educ. 2011, 35, 34-38.

42. Gioia, D.A.; Corley, K.G.; Hamilton, A.L. Seeking Qualitative Rigor in Inductive Research: Notes on the Gioia Methodology. Organ. Res. Methods 2013, 16, 15-31. [CrossRef]

43. Nag, R.; Gioia, D.A. From common to uncommon knowledge: Foundations of firm-specific use of knowledge as a resource. Acad. Manag. J. 2012, 55, 421-457. [CrossRef]

44. Toloie-Eshlaghy, A.; Chitsaz, S.; Karimian, L.; Charkhchi, R. A Classification of Qualitative Research Methods. Res. J. Intern. Stud. 2011, 20, 106-123.

45. Lacy, S.; Watson, B.R.; Riffe, D.; Lovejoy, J. Issues and Best Practices in Content Analysis. J. Mass Comm. Q. 2015, 92, 791-811. [CrossRef]

46. Oppliger, P.A.; Davis, A. Portrayals of Bullying: A Content Analysis of Picture Books for Preschoolers. Early Child. Educ. J. 2015, 44, 515-526. [CrossRef]

47. Horton, J.; Macve, R.; Struyven, G. Qualitative Research: Experiences in Using Semi-Structured Interviews. In The Real Life Guide to Accounting Research, A Behind-the-Scenes View of Using Qualitative Research Methods; Humphrey, C., Lee, B., Eds.; Elsevier Ltd.: Oxford, UK, 2004; pp. 339-350.

48. Elo, S.; Kääriäinen, M.; Kanste, O.; Pölkki, T.; Utriainen, K.; Kyngäs, H. Qualitative Content Analysis: A Focus on Trustworthiness SAGE Open Jan. Mar. 2014. [CrossRef]

49. Elo, S.; Kyngäs, H. The qualitative content analysis process. J. Adv. Nurs. 2008, 62, 107-115. [CrossRef] [PubMed]

50. Cavanagh, S. Content analysis: Concepts, methods and applications. Nurse Res. 1997, 4, 5-16. [CrossRef] [PubMed]

51. Mayring, P. Qualitative Content Analysis. Forum Qual. Soc. Res. 2000, 1, 20.

52. Krippendorff, K. Content Analysis: An Introduction to Its Methodology, 2nd ed.; Sage: Thousand Oaks, CA, USA, 2004.

53. Erss, M.; Kalmus, V.; Autio, T.H. 'Walking a fine line': Teachers' perception of curricular autonomy in Estonia, Finland and Germany. J. Curric. Stud. 2016, 48, 589-609. [CrossRef]

54. Cansoy, R.; Parlar, H. Examining the Relationship between School Culture and Teacher Leadership. Intern. Online J. Educ. Sci. 2017, 9, 310-322. [CrossRef] 
55. Pittaway, L.; Cope, J. Simulating Entrepreneurial Learning Integrating Experiential and Collaborative Approaches to Learning. Manag. Learn. 2007, 38, 211-233. [CrossRef]

56. Leffler, E. The Many Faces of Entrepreneurship: A discursive battle for the school arena. Eur. Educ. Res. J. 2009, 8, 104-116. [CrossRef]

57. Salonen-Hakomäki, S.-M.; Soini, T.; Pietarinen, J.; Pyhältö, K. The way ahead for Finnish comprehensive school? Examining state-level school administrator's theory of change. J. Curric. Stud. 2016, 48, 671-691. [CrossRef]

58. Ruskovaara, E. Entrepreneurship Education in Basic and Upper Secondary Education-Measurement and Empirical Evidence. Ph.D. Thesis, Lappeenranta University of Technology, Lappeenranta, Finland, 2014. Available online: http:/ / urn.fi/URN:ISBN: 978-952-265-657-5 (accessed on 15 January 2021).

59. Fisher-Ari, T.R.; Lynch, H.L. Archeology, legos, and haunted houses: Novice teachers' shifting understandings of self and curricula through metaphor. J. Curric. Stud. 2015, 47, 529-552. [CrossRef]

60. Lappalainen, S.; Lahelma, E. Subtle discourses on equality in the Finnish curricula of upper secondary education: Reflections of the imagined society. J. Curric. Stud. 2016, 48, 650-670. [CrossRef]

61. Shao-Wen, S. The Various Concepts of Curriculum and the Factors Involved in Curricula-making. J. Lang. Teach. Res. 2012, 3, 153-158.

62. Seikkula-Leino, J. The implementation of entrepreneurship education through curriculum reform in Finnish comprehensive schools. J. Curric. Stud. 2011, 43, 69-85. [CrossRef]

63. European Commission. Entrepreneurship Education at School in Europe; European Commission, Publications Office of the European Union: Brussels, Belgium, 2016.

64. Hopman, M.; de Winter, M.; Koops, W. The hidden curriculum of youth care interventions-A case study. Child. Youth Serv. Rev. 2012, 35, 237-243. [CrossRef]

65. Frank, A.I. Three Decades of Thought on Planning Education. J. Plan. Lit. 2006, 21, 15-67. [CrossRef]

66. Frank, A.I. Entrepreneurship and enterprise skills: A missing element of planning education? Plan. Pr. Res. 2007, 22, 635-648. [CrossRef] 